\title{
CARACTERIZAÇÃO AMBIENTAL DA MICROBACIA DO RIO BUQUIRA NO TRECHO DO BAIRRO COSTINHA AO MIRANTE DO BUQUIRINHA
}

\section{Aline Santos ${ }^{1}$ \\ Carolina Ribeiro ${ }^{2}$ \\ Maria Regina Aquino-Silva ${ }^{3}$}

Resumo: Este artigo tem como finalidade analisar a microbacia, do Rio Buquira (que é o maior afluente, da margem esquerda, do Rio Paraíba do Sul), situada na região Norte da cidade de São José dos Campos$S P$, onde os loteamentos Costinha e Mirante do Buquirinha se encontram. Tais loteamentos apresentam periodicamente eventos de enchentes; a fim de entender e explicar melhor o motivo desses acontecimentos nestas áreas foi feita a caracterização das áreas de risco através dos dados georreferênciados utilizados para elaboração dos mapas temáticos com o auxilio dos softwares ArcMap 10 e Google Earth Pro. Através dos dados, observou-se os prováveis motivos da vulnerabilidade ambiental nas áreas analisadas.

Palavras-chave: Rio Buquira, vulnerabilidade ambiental, APP.

\footnotetext{
${ }^{1}$ Universidade do Vale do Paraíba/Engenharia Ambiental e Sanitária, Av. Shishima Hifumi, 2911- Urbanova- São José dos Campos - SP, Brasil. E-mail: alineads011@gmail.com.

2 Universidade do Vale do Paraíba/Engenharia Ambiental e Sanitária, Av. Shishima Hifumi, 2911- Urbanova- São José dos Campos - SP, Brasil. E-mail: carol15_souza@hotmail.com.

${ }^{3}$ Universidade do Vale do Paraíba/IP\&D, Av. Shishima Hifumi, 2911 - Urbanova - São José dos Campos - SP, Brasil. E-mail: mregina@univap.br.
} 